Zwaanswijk, M., Ende, J. van der, Verhaak, P.F.M., Bensing, J.M., Verhulst, F.C. The different stages and actors involved in the process leading to the use of adolescent mental health services. Clinical Child Psychology and Psychiatry: 2007, 12(4), 567-582

\begin{tabular}{|l|l|}
\hline Postprint Version & 1.0 \\
\hline Journal website & $\underline{\text { http://ccp.sagepub.com/cgi/reprint/12/4/567 }}$ \\
\hline Pubmed link & $\underline{\text { http://www.ncbi.nlm.nih.gov/pubmed/18095538 }}$ \\
\hline DOI & $10.1177 / 1359104507080985$ \\
\hline
\end{tabular}

This is a NIVEL certified Post Print, more info at http://www.nivel.eu

\title{
The Different Stages and Actors Involved in the Process Leading to the Use of Adolescent Mental Health Services
}

\author{
MARIEKE ZWAANSWIJK ${ }^{1,2}$, JAN VAN DER ENDE ${ }^{2}$, PETER F.M. VERHAAK ${ }^{1,3}$, JOZIEN M. \\ BENSING $^{1}$, FRANK C. VERHULST $^{2}$ \\ 1 NIVEL \\ 2 Erasmus Medical Centre, The Netherlands \\ 3 Utrecht University
}

\begin{abstract}
Although a substantial number of adolescents suffer from emotional or behavioural problems, only a minority receive mental health care. In order to understand this discrepancy, this article aims to increase insight into the help-seeking process.

First, a model of the help-seeking process for adolescent psychopathology was formulated. This model takes into account the sequential nature of help seeking and the involvement of multiple actors (adolescents, parents and teachers) and service providers (general practitioners, mental health care professionals, teachers, and friends/relatives). Using structural equation modelling, the model was empirically tested on 114 Dutch adolescents (aged 12-17 years), who were selected for having emotional or behavioural problems from a representative general practice sample. Of these $16.5 \%$ had used mental health services. The sequence of stages and the actors involved in the process leading to mental health care use was similar across gender. Parents and adolescents had a comparable impact on this process.

The general practitioner functioned as gatekeeper to mental health care, whereas the teacher's role in the process was limited. Interventions aimed at increasing adolescent mental health service use should be directed at parents and adolescents, and at the roles of school personnel and general practitioners in the detection of problems and referral.
\end{abstract}

A SUBSTANTIAL NUMBER of adolescents suffer from emotional or behavioural disorders (Verhulst, Van der Ende, Ferdinand, \& Kasius, 1997) which can hamper their present and future functioning and wellbeing (Costello, Angold, \& Keeler, 1999; Sawyer et al., 2001). This creates a burden for them and their families, as well as for society as a whole. Moreover, rates of adolescent psychiatric disorders appear to be rising in many western countries (Maughan, Iervolino, \& Collishaw, 2005). In spite of this, the majority of these adolescents do not receive specialist mental health care, whereas the use of these services in adolescence may be particularly important for preventing the persistence of psychopathology into adulthood (cf. Feehan, McGee, \& Stanton, 1993; Harrington, Rutter, \& Fombonne, 1996). In a study among Dutch adolescents (Zwaanswijk, Van der Ende, Verhaak, Bensing, \& Verhulst, 2003), merely 8\% of adolescents, who perceived themselves as having serious emotional or behavioural problems, had been referred for mental health services in the preceding year. A Finnish study using the same self-report measure for the presence of psychopathology, reported a referral rate of $13 \%$. The referral rate was somewhat higher when parents' reports of adolescent psychopathology were used. Here, $28 \%$ of adolescents, whose parents reported the presence of psychopathology, had been in contact with mental 
Zwaanswijk, M., Ende, J. van der, Verhaak, P.F.M., Bensing, J.M., Verhulst, F.C. The different stages and actors involved in the process leading to the use of adolescent mental health services. Clinical Child Psychology and Psychiatry: 2007, 12(4), 567-582

health services (Sourander et al., 2001). A similar discrepancy between rates of psychopathology and mental health service use was found in an Australian sample (Sawyer et al., 2000).

The process leading to the use of services is generally thought of as a sequence of stages (Andersen, 1995; Costello, Pescosolido, Angold, \& Burns, 1998; Goldberg \& Huxley, 1992; Logan \& King, 2001; Verhulst $\&$ Koot, 1992). Previous research has, however, predominantly focused on isolated help-seeking stages, whereas a thorough understanding of the help-seeking process requires insight into the relations between the different stages of seeking help, and into the various actors involved. The present study therefore aims to test a model of the process of help seeking for adolescent psychopathology in professional and informal service settings (Figure 1). Since gender differences occur in the prevalence rates of adolescent emotional and behavioural disorders, differences may exist in the help-seeking processes of both genders. Thus, the applicability of the model across gender is investigated.

[figure 1]

\section{The help-seeking model}

Hypothesized associations between the different stages of seeking help are based upon a previous model on help seeking for primary school children's psychopathology (Zwaanswijk, Van der Ende, Verhaak, Bensing, \& Verhulst, 2005). The first step in the help-seeking process is assumed to be an initial awareness by parents or adolescents, of the presence of adolescent problems (Logan \& King, 2001), followed by the acknowledgement that these problems are severe enough to require outside help (service need).

Awareness of service need is hypothesized to precede help seeking. Help seeking is investigated in both professional (general practice, mental health care) and informal service settings (teachers, friends/relatives). The use of informal service providers may be particularly important in the process of help seeking for adolescent psychopathology (Rickwood \& Braithwaite, 1994). The threshold for seeking help from friends or relatives is considered to be lower than for any other kind of service. Therefore, we assume that this kind of help-seeking behaviour precedes the use of other services.

Since general practice is the formal point of entry into Dutch mental health care, and general practitioners (GPs) are supposed to function as gatekeepers, a central role in the help-seeking process is attributed to the GP. Dutch general practices are accessible to all, close to the community, and GPs provide general care.

Although the processes of help seeking for child and adolescent psychopathology are comparable with regard to the stages involved, differences are likely to exist in the actors involved in both processes. Therefore, the previously stated model by Zwaanswijk et al.

(2005) cannot be applied directly to adolescents. Whereas parents continue to play an important role in initiating the use of services for adolescents (cf. Sourander et al., 2001; Zwaanswijk et al., 2003), as they did for younger children, adolescents' increasing autonomy strengthens their influence on the help-seeking process. As teachers may also be able to increase the awareness of the need to seek help (cf. Stanger \& Lewis, 1993), their perception of the presence of problems is included in the model as well.

This study aims to provide a more thorough understanding, both of the sequence of help-seeking stages and of the actors and service providers involved in help seeking for adolescent psychopathology. Because of differences between health care systems, our theoretical model may not be directly applicable to nations in which mental health care can be entered without a GP's referral. Nevertheless, by testing a help-seeking model as a whole, instead of investigating its separate parts, we believe we can provide a more generic method for studying help seeking in different kinds of health care systems.

\section{METHOD}

\section{Study population and procedure}

The study involved a two-stage procedure. An overview of the study design and the numbers of respondents in the various stages of the study are presented in Figure 2. The base population of the study was derived from the Second Dutch National Survey of General Practice, which examined morbidity and treatment in a representative sample of 104 general practices with 195 GPs and 385,461 listed patients, between April 2000 and January 2002 (Westert et al., 2005). A random sample of the practice population was asked to participate in an extensive health interview survey. The total response rate was $64.5 \%$. Participants in this survey were comparable to the practice population with respect to gender, age and place of residence (Westert et al., 2005).

As part of this interview, parents completed the Child Behavior Checklist (CBCL; Achenbach, 1991a) and adolescents completed the Youth Self-report (YSR; Achenbach, 1991c). Responses were received from a 
Zwaanswijk, M., Ende, J. van der, Verhaak, P.F.M., Bensing, J.M., Verhulst, F.C. The different stages and actors involved in the process leading to the use of adolescent mental health services. Clinical Child Psychology and Psychiatry: 2007, 12(4), 567-582

total number of 830 adolescents. Data were available from 810 parents and 814 adolescents. Respondents were asked permission to send the Teacher's Report Form (TRF; Achenbach, 1991b) to the teacher who was the most familiar with the adolescent's functioning. Responses were received from 507 teachers $(213$ respondents refused to give permission to contact the teacher, 28 teachers refused to co-operate, 67 teachers did not respond, 13 adolescents did not attend school, and 2 teachers could not be contacted due to gaps in the list of school addresses).

Adolescents with available and missing TRF data were comparable with respect to gender, and CBCL and YSR Total Problems scores. Adolescents for whom TRF data were missing were slightly older than adolescents with available TRF data $(M s=14.5$ vs $14.1 ; t=3.42 ; d f=939 ; p<.01)$.

Adolescents scoring in the deviant range of the CBCL, TRF or YSR Total Problems scale $(T \geq 60)$ were selected for participation in the second stage of the study. Of the 191 selected adolescents, 114 (50.9\% boys, $49.1 \%$ girls) agreed to participate. 113 CBCLs, 110 YSRs, and 84 TRFs were available. Second-stage respondents and nonrespondents were comparable with respect to age, gender, CBCL and TRF Total Problems scores.

[figure 2]

However, subjects who did not participate had higher YSR Total Problems scores ( $M \mathrm{~s}=39.3 \mathrm{vs} 46.2 ; t=$ $2.38 ; d f=182 ; p=.02)$.

In the second stage, the adolescent and his or her primary caregiver were interviewed, using a standardized psychiatric interview (DISC-IV; Shaffer, Fisher, Christopher, Dulcan, \& Schwab-Stone, 2000), in order to obtain adolescent psychiatric diagnoses.

Data from the psychiatric interviews were available from 96 adolescents and 110 parents.

Parents were also interviewed about seeking help for adolescent problems in the preceding 12 months. Data were available from 109 parents.

\section{Measures}

Parent, adolescent, and teacher perceptions of the presence of adolescent problems over the 6 months preceding the first-stage assessment were measured using validated Dutch translations of the CBCL (Achenbach, 1991a), YSR (Achenbach, 1991c), and TRF (Achenbach, 1991b), respectively. These instruments consist of 120 itemized problems (YSR: 102), which yield scores for Total Problems, Internalizing and Externalizing Problems, and eight syndrome scores. The Total Problems scores were used as indicators of parents', teachers', and adolescents' initial awareness of the presence of adolescent problems.

Adolescent and parent perceptions of the need to access services were assessed by the National Institute of Mental Health Diagnostic Interview Schedule for Children, version 4 (DISC-IV), parent version (DISC-P) and youth version (DISC-Y). This structured interview is designed to assess psychiatric disorders in children and adolescents, using DSM-IV criteria (American Psychiatric Association (APA), 1994). Sections concerning anxiety disorders, mood disorders, and disruptive behaviour disorders were used to obtain a measure of service need, which was composed of the informant's perception of the presence of psychopathology and associated functional impairment (cf. Brewin, Wing, Mangen, Brugha, \& MacCarthy, 1987). Impairment was considered to be present when at least 2 out of 6 diagnosis-specific impairment items indicating moderate, or one item indicating severe personal distress, social or academic difficulties, were present. This indicator corresponds more with formal diagnostic criteria rather than measures of need used in previous studies in which respondents are directly asked whether they are in need of help.

During the second-stage interview parents were asked whether help from GPs, mental health care professionals (e.g. psychologists, psychiatrists), teachers and friends or relatives, had been used for adolescent emotional or behavioural problems in the preceding 12 months.

\section{Statistical analyses}

Structural equation modelling (AMOS 4.0; Arbuckle \& Wothke, 1999) was used to test whether the theoretical model applied to our data. To ensure an adequate amount of estimated parameters in relation to the limited sample size $(N=114)$, only observed variables were included in the model.

In contrast to traditional multiple regression analyses, structural equation modelling provides the opportunity to include, simultaneously, several dependent variables in one model. This reduces the number of separate tests that have to be performed, and consequently reduces the risk of capitalization on chance as well. The general model (Figure 1) was first tested and modified to increase the fit. Multigroup analyses 
Zwaanswijk, M., Ende, J. van der, Verhaak, P.F.M., Bensing, J.M., Verhulst, F.C. The different stages and actors involved in the process leading to the use of adolescent mental health services. Clinical Child Psychology and Psychiatry: 2007, 12(4), 567-582

were then performed to test the applicability of the model across gender. Apart from the traditionally used chi-square, the model's fit was evaluated by means of two additional indices.

The Root Mean Square Error of Approximation (RMSEA) represents the average difference between correlations observed among variables and those expected on the basis of model assumptions. It also takes into account model parsimony. A value $<.05$ was considered to indicate a close fit for the model (Browne \& Cudeck, 1993). The non normed fit index (NNFI; Bentler \& Bonett, 1980) or Tucker-Lewis coefficient (TLI; Tucker \& Lewis, 1973) indicates the overall fit of the proposed model relative to a null model, adjusting for model complexity. A value close to 1 indicates a very good fit.

Adolescents were selected for participation in the second stage of the study based on deviant Total Problems scores on at least 1 of 3 separate measures (CBCL, TRF, and YSR). Therefore not all adolescents had deviant scores on each of these measures (Table 1).

We explicitly chose to perform analyses on the whole range of Total Problems scores instead of restricting analyses to adolescents scoring in the deviant range. This was because emotional and behavioural problems that do not reach deviant levels may also result in the need to access services. The severity of problems was incorporated in the help-seeking model by including Total Problems scores as continuous rather than dichotomous variables.

\section{RESULTS}

To gain insight into the severity of problems in our sample, the numbers of adolescents with CBCL, YSR and TRF Total Problems scores in the deviant range are reported in Table 1. The continuous rather than dichotomous scores on these scales were used in the structural equation model. The means and standard deviations of continuous Total Problems scores are reported in Table 2. The gender differences in the rates of adolescent problems were not significant, both when dichotomous, as well as when continuous Total Problems scores were considered. There was limited agreement between informants' perceptions of the presence of problems (Table 1).

Based on their parents' reports (DISC-P), 36/110 (32.7\%) adolescents met criteria for DSM-IV disorders, with a total of 60 psychiatric disorders being present in the sample (Table 3). Based on their self-reporting (DISC-Y), 21/96 (21.9\%) adolescents had DSM-IV disorders, with a total of 36 psychiatric disorders being reported. The majority of adolescents with disorders $(65.0 \%$ for parents' reports, $77.8 \%$ for adolescents' reports) had emotional disorders (DISC-IV anxiety and mood disorders; Table 3). The predominance of emotional disorders was particularly marked in girls. Comorbidity was present in less than half of adolescents with DISC-P disorders (41.7\%) or DISC-Y disorders (38.1\%).

Service need was considered to be present when adolescents' psychiatric diagnoses were accompanied by considerable functional impairment (see Measures). The rates of service need and service use are reported in Table 4. Gender differences in these rates were not significant. There was limited agreement between parents' and adolescents' perceptions of the presence of a need for services.

Of the 67 adolescents whose parents indicated the presence of CBCL Total Problems in the deviant range, 15 were also regarded by their parents to need services. Of the 27 adolescents who reported YSR Total Problems scores in the deviant range, eight also reported a need for services.

Of the 18 adolescents who had received mental health services in the preceding year, $11(61.1 \%)$ had entered mental health care after referral by their GP. The remaining seven adolescents had obtained mental health services either directly $(N=3)$, or with the help of other service providers, such as the school physician or paediatrician $(N=4)$.

\section{Evaluation of the path model}

The initial theoretical model (Figure 1) did not adequately fit the data (Model A, Table 5). To increase model fit, nonsignificant paths were deleted from the model one by one, resulting in Model B (Table 5). Consequently, modification indices were inspected.

Because these indices cannot be computed with incomplete data, they were computed for the part of the sample with complete data $(N=79)$. All other structural equation modelling analyses were performed on the sample as a whole $(N=114)$. Only one of the suggested associations - a covariance between parent and adolescent reports of problems - was theoretically relevant and was therefore added to the model (Model C, Table 5).

Finally, regression weights of equivalent associations for parents and adolescents were constrained to be equal. These included the associations between parent/adolescent reports of problems and service need; 
Zwaanswijk, M., Ende, J. van der, Verhaak, P.F.M., Bensing, J.M., Verhulst, F.C. The different stages and actors involved in the process leading to the use of adolescent mental health services. Clinical Child Psychology and Psychiatry: 2007, 12(4), 567-582

between parental/adolescent service need and GP consultation; and between parental/adolescent service need and help seeking from friends or relatives. The results of a chi-square difference test, which showed no significant differences between the resulting model $\mathrm{D}$ (Table 5) and the unconstrained Model $\mathrm{C}\left(\Delta \chi_{2}=\right.$ $2.88 ; d f=3 ; p>.05)$, were in favour of the more parsimonious Model D.

\section{[TABLE 1] [TABLE 2] [TABLE 3] [TABLE 4] [TABLE 5]}

To test the applicability of the model across gender, multigroup analyses were performed on the general model (Model D). We first tested a model in which all paths were estimated independently for boys and girls. Thus, the constraints that were imposed in Model D were retained within the groups of boys and girls, but between these groups, the parameters were allowed to vary. The resulting model adequately fits the data (Model E,Table 5). Next, coefficients were constrained to be identical between boys and girls, only when this resulted in a significant improvement of model fit. All coefficients could be constrained to be equal across gender, except for the association between seeking help from the teacher and mental health service use, which was stronger for girls than for boys. Because no significant differences were found between the resulting Model F (Table 5) and Model E, in which no constraints between genders were included $\left(\Delta \chi_{2}=\right.$ $4.76 ; d f=7 ; p>.05)$, the more parsimonious Model $\mathrm{F}$ was chosen as the best fitting model. The standardized regression weights and correlations for the final model are depicted in Figure 3. Equality constraints are imposed upon nonstandardized instead of standardized coefficients. Therefore, even when no significant gender differences were found for equivalent associations, the standardized coefficients for these associations are not entirely identical across gender (Figure 3).

\section{[FIGURE 3]}

\section{DISCUSSION}

This study was aimed at investigating the process of help seeking for adolescent psychopathology.

By means of structural equation modelling, a path model was evaluated that takes into account the sequential nature of help seeking and the involvement of multiple actors and service providers.

In general, the study confirmed previous findings concerning the limited use of mental health care by adolescents with emotional and behavioural problems (Saunders, Resnick, Hoberman, \& Blum, 1994; Sourander et al., 2001; Zwaanswijk et al., 2003).

Even in a sample that was selected for the presence of such problems, just $16.5 \%$ of adolescents had used mental health services in the preceding year. Insight into the pathways through which disordered adolescents are able to find their way into mental health care may provide suggestions on how to increase the use of mental health services.

Our results confirmed adolescents' increasing autonomy, as well as parents' continuing influence, as both exerted a considerable influence on the help-seeking process. Both influences were remarkably similar, given the limited overlap between adolescent and parental perceptions of the presence of problems or need.

The positive associations between parent and adolescent reporting of problems and service need indicate that more severe problems are associated with a greater likelihood of service need. However, only a minority of adolescents with deviant Total Problems scores (22.4\% based on parents' reports, and $29.6 \%$ based on adolescents' reports) were regarded also to be in need of services. The failure to acknowledge the need to seek help when emotional or behavioural problems are present could therefore be regarded as a first obstacle in the help-seeking process. The discrepancy between parent/adolescent problem reports and the need for services may also indicate that emotional and behavioural problems are to some extent regarded as normal during adolescence (Offer \& Schonert-Reichl, 1992), and therefore may be regarded not to require special care.

Although some adolescents will indeed have enough resources to cope with their problems, others may benefit from care, even when they do not acknowledge a need for help.

Mobilizing teachers to increase parents' or adolescents' awareness of the severity of problems and the need for outside help does not, however, seem to be the best strategy.

In contrast with findings for primary-school children (Zwaanswijk et al., 2005), teachers' perceptions of problems did not affect parents' or adolescents' need for services. A comparable difference between the roles of schools in the processes of help seeking for children and adolescents was found in another study (Ford, Hamilton, Goodman, \& Meltzer, 2005). Here parents of younger children were more likely to have 
Zwaanswijk, M., Ende, J. van der, Verhaak, P.F.M., Bensing, J.M., Verhulst, F.C. The different stages and actors involved in the process leading to the use of adolescent mental health services. Clinical Child Psychology and Psychiatry: 2007, 12(4), 567-582

been in contact with teachers even though psychiatric disorders were more common in older children. This finding can probably be ascribed to the fact that, in contrast with secondary-school pupils, primary-school children have one teacher, who may therefore have a better opportunity to get well acquainted with the pupils. Moreover, primaryschool children are often taken to and from school, thereby facilitating informal contact between teachers and parents.

The limited role of the teacher in the help-seeking process of adolescents can probably also be ascribed to the type of adolescent problems concerned. The majority of adolescents in our sample had emotional disorders, reflecting the general predominance of emotional over behavioural disorders in adolescence. Behavioural problems, which cause direct disturbance in the classroom, may be more easily detected by secondaryschool teachers than the more covert emotional problems.

Despite gender differences in the prevalence of types of DISC-IV disorders, with behavioural disorders being present mainly in boys, and a predominance of emotional disorders in girls (Table 3), the helpseeking processes of both genders were remarkably similar. This demonstrates robustness of our model. The only difference between genders was the stronger association between help seeking from the teacher and mental health care use for girls.

Both the regression weights in our path model (Figure 3), and the inspection of mental health referrals, confirmed the gate-keeping function of the Dutch GP. Most adolescents (61.1\%), who had received mental health services in the preceding year, had entered this care after referral by their GP. This finding is in contrast with findings for Dutch primaryschool children (Zwaanswijk et al., 2005), of whom the majority $(56.8 \%)$ had entered mental health care through pathways other than GP referral. They had obtained mental health care mainly with the help of service providers based in schools. Apparently, Dutch GPs function more according to their formal role as the gate keeper to mental health care in the process of help seeking for adolescent than for child psychopathology. This increase in the GPs' role might be explained by an association between adolescent emotional problems and somatic complaints (Kramer \& Garralda, 1998), which could increase GP consultation in general.

\section{Limitations}

Caution should be exercised in generalizing the present findings to health care systems in which the GP does not function as the gate keeper to mental health care, or in which paediatricians or whole-service schools play a major role in handling mental health problems. We believe, however, that the merits of this method are not restricted to countries with comparable health care systems, such as the UK. We consider it is also useful as a more generic approach for clarifying the help-seeking processes in other countries, as it takes into account the multiple stages and actors involved in these processes. We therefore advocate using our method with help-seeking models adapted to other health care systems. Moreover, we believe our results concerning parents' and adolescents' impacts on the help-seeking process, and the way the model can be applied equally across genders, to be of more general value.

For the sake of simplicity, the model only incorporated progress along the pathway to service use. In reality, progress towards service use has a more dynamic character.

Parents or adolescents may revert back to previous steps in the help-seeking process when they encounter particularly strong barriers on the pathway to care. For instance, when a parent's suggestion to seek mental health care is met by a considerable amount of resistance from the adolescent, parents may reconsider the, previously experienced, need for care and progress on the pathway to care may be temporarily or permanently halted. Barriers against seeking help may be practical issues (e.g. long waiting lists or not knowing where to get help), parents' or adolescents' attitudes towards mental health problems (e.g. denial or hope for spontaneous improvement), or their perceptions of services or service providers. Concern about the attitude of others has been shown to constitute only a minor barrier to help seeking (Pavuluri, Luk, \& McGee, 1996; Sawyer et al., 2000).

The limited sample size prohibited the concurrent testing of determinants of the helpseeking process. Further research on this matter will improve our understanding of variables influencing adolescent help seeking, thereby possibly providing directions for interventions. Replication of our results in future studies, preferably longitudinal ones, is also required to confirm the findings and establish causal directionality of the associations found.

Generalizability may be hampered by the fact that adolescents with high self-reported Total Problems were less likely to participate in the study. As high YSR Total Problems scores are usually associated with an increased chance of service need and mental health referral (Zwaanswijk et al., 2003), high-scoring adolescents' reluctance to participate in this study may have caused rates of self-reported service need and 
Zwaanswijk, M., Ende, J. van der, Verhaak, P.F.M., Bensing, J.M., Verhulst, F.C. The different stages and actors involved in the process leading to the use of adolescent mental health services. Clinical Child Psychology and Psychiatry: 2007, 12(4), 567-582

help seeking to be underestimated. However, the absence of selective attrition for parents' reports of adolescent problems, and the fact that the rates of service use were based upon parents' reports only, argues against the possibility of underestimating help-seeking rates.

One of the strengths of this study is the inclusion of parents' and adolescents' reports of problems and service need. However, information regarding service use was obtained from parents only, which may not adequately reflect adolescent service use. Reports of the use of friends or relatives are particularly likely to vary, because of differences between the social networks of parents and adolescents. Since this type of help is regarded as important for adolescents as part of their increasing autonomy (cf. Rickwood \& Braithwaite, 1994; Saunders et al., 1994), future studies should include adolescent reports of service use.

\section{Clinical implications}

This study allowed several groups to be identified towards whom interventions to increase the use of adolescent mental health services may be directed. First, taking into account parents' and adolescents' impacts on the help-seeking process, interventions aimed at increasing service use should be directed at both. Educating parents and adolescents about the nature and prevalence of emotional and behavioural problems may be useful to raise their awareness of the presence of such problems and of the need to seek help. Parents and adolescents, who do feel a need for care that is not translated into service use, may be provided with information on the availability and accessibility of care.

An increase in the rates of adolescent mental health service use may also be accomplished by further improving GPs' skills in detecting adolescent emotional and behavioural problems (cf. Walker \& Townsend, 1998). Identification of these problems may be increased by teaching GPs to use psychosocially oriented interview techniques, which facilitate disclosure of sensitive information concerning mental health, and educating them to elicit adolescent concerns about their mental health (cf. Sayal \& Taylor, 2004; Wissow, Roter, \& Wilson, 1994). In general, evaluations tend to show the benefits of training to increase skills and confidence (e.g. Gledhill, Kramer, Iliffe, \& Garralda, 2003; Luk, Brann, Sutherland, Mildred, \& Birleson, 2002), but trials have not been methodologically rigorous and need to be elaborated (Garralda, 2004). Identification of adolescent mental health problems may also be enhanced by the introduction of standardized screening measures in general practice (cf. Horwitz, Leaf, Leventhal, Forsyth, \& Speechley, 1992).

Efforts to increase GPs' identification of adolescent mental health problems should be accompanied by good opportunities to refer adolescents. In general, direct contact between GPs and mental health professionals facilitates referral and accelerates access to services (cf. Luk et al., 2002), because it provides the opportunity to discuss directly the availability of specialist care. Direct contact between GPs and mental health care specialists should also be encouraged because of its consultative function.

The limited role of school personnel in the process of help seeking for adolescent psychopathology may be expanded through direct contact between schools and mental health care professionals, which may ameliorate problem detection within schools and shorten the pathway to specialist care. Moreover, external professionals may provide less intensive forms of care within schools. The school setting probably offers a sense of familiarity, accessibility and acceptability to adolescents, which may be harder to achieve in an outpatient mental health clinic.

Progress on the pathway to care may be hindered by parents' or adolescents' attitudes towards mental health problems, and their perceptions of services or service providers (Pavuluri et al., 1996). By teaching GPs and school personnel strategies for addressing these restraints, adolescents' access to mental health care may be improved.

The multitude of services available for youth in general, and youngsters with emotional or behavioural problems in particular, creates the risk of a fragmented system of care, in which families have to deal with a wide variety of services, each with their own rules, staff, and procedures. Because the majority of children and adolescents with emotional or behavioural problems use a combination of services (Farmer, Burns, Phillips, Angold, \& Costello, 2003; Ford et al., 2005), inter-agency collaboration among the education sector, primary health care, and specialty mental health services is crucial. 
Zwaanswijk, M., Ende, J. van der, Verhaak, P.F.M., Bensing, J.M., Verhulst, F.C. The different stages and actors involved in the process leading to the use of adolescent mental health services. Clinical Child Psychology and Psychiatry: 2007, 12(4), 567-582

\section{REFERENCES}

Achenbach,T.M. (1991a). Manual for the Child Behavior Checklist/4-18 and 1991 Profiles. Burlington,VT: University of Vermont Department of Psychiatry.

Achenbach,T.M. (1991b). Manual for the Teacher's Report Form and 1991 Profiles. Burlington,VT:

University of Vermont Department of Psychiatry.

Achenbach,T.M. (1991c). Manual for the Youth Self-report and 1991 Profiles. Burlington, VT: University of Vermont Department of Psychiatry.

American Psychiatric Association. (APA). (1994). Diagnostic and statistical manual of mental disorders (4th Ed.). Washington, DC: Author.

Andersen, R.M. (1995). Revisiting the behavioral model and access to medical care: Does it matter? Journal of Health and Social Behavior, 36, 1-10.

Arbuckle, J.L., \& Wothke,W. (1999). Amos 4.0 user's guide. Chicago: SmallWaters.

Bentler, P.M., \& Bonett,D.G. (1980). Significance tests and goodness of fit in the analysis of covariance structures. Psychological Bulletin, 88, 588-606.

Brewin, C.,Wing, J., Mangen, S., Brugha,T., \& MacCarthy, B. (1987). Principles and practice of measuring needs in the long-term mentally ill: The MRC Needs for Care Assessment.

Psychological Medicine, 17, 971-981.

Browne, M.W., \& Cudeck, R. (1993). Alternative ways of assessing model fit. In K.A. Bollen \& J.S. Long (Eds.), Testing structural equation models (pp. 136-162). Newbury Park, CA: SAGE Publications.

Costello, E.J., Angold, A., \& Keeler,G.P. (1999). Adolescent outcomes of childhood disorders: The consequences of severity and impairment. Journal of the American Academy of Child and Adolescent Psychiatry, 38, 121-128.

Costello, E.J., Pescosolido, B.A., Angold, A., \& Burns, B.J. (1998). A family network-based model of access to child mental health services. Research in Community and Mental Health, 9, 165-190.

Farmer, E.M.Z., Burns, B.J., Phillips, S.D., Angold, A., \& Costello, E.J. (2003). Pathways into and through mental health services for children and adolescents. Psychiatric Services, 54, 60-66.

Feehan, M., McGee, R., \& Stanton,W. (1993). Helping agency contact for emotional problems in childhood and early adolescence and the risk of later disorder. Australian and New Zealand Journal of Psychiatry, 27, 270-274.

Ford,T., Hamilton, H., Goodman, R., \& Meltzer, H. (2005). Service contacts among the children participating in the British Child and Adolescent Mental Health Surveys. Child and Adolescent Mental Health, 10, 2-9.

Garralda, M.E. (2004). The interface between physical and mental health problems and medical help seeking in children and adolescents: A research perspective. Child and Adolescent Mental Health, 9, 146-155.

Goldberg,D., \& Huxley, P. (1992). Common mental disorders: A bio-social model. London: Routledge.

Gledhill, J., Kramer,T., lliffe, S., \& Garralda, M.E. (2003). Training general practitioners in the identification and management of adolescent depression within the consultation: A feasibility study. Journal of Adolescence, 26, 245-250.

Harrington, R., Rutter, M., \& Fombonne, E. (1996). Developmental pathways in depression: Multiple meanings, antecedents, and endpoints. Developmental Psychopathology, 8, 601-616.

Horwitz, S.M., Leaf, P.J., Leventhal, J.M., Forsyth, B., \& Speechley, K.N. (1992). Identification and management of psychosocial and developmental problems in community-based, primary care pediatric practices. Pediatrics, 89, 480-485.

Kramer,T., \& Garralda, M.E. (1998). Psychiatric disorders in adolescents in primary care.

British Journal of Psychiatry, 173, 508-513.

Logan,D.E., \& King, C.A. (2001). Parental facilitation of adolescent mental health service utilisation: A conceptual and empirical review. Clinical Psychology: Science and Practice, 8, 319-333.

Luk, E.S.L., Brann, P., Sutherland, S., Mildred, H., \& Birleson, P. (2002). Training general practitioners in the assessment of childhood mental health problems. Clinical Child Psychology and Psychiatry, 7, 571579.

Maughan, B., lervolino,A.C., \& Collishaw, S. (2005). Time trends in child and adolescent mental disorders. Current Opinion in Psychiatry, 18, 381-385.

Offer,D., \& Schonert-Reichl, K.A. (1992). Debunking the myths of adolescence: Findings from recent research. Journal of the American Academy of Child and Adolescent Psychiatry, 31, 1003-1014. 
Zwaanswijk, M., Ende, J. van der, Verhaak, P.F.M., Bensing, J.M., Verhulst, F.C. The different stages and actors involved in the process leading to the use of adolescent mental health services. Clinical Child Psychology and Psychiatry: 2007, 12(4), 567-582

Pavuluri, M.N., Luk, S., \& McGee, R. (1996). Help-seeking for behavior problems by parents of preschool children: A community study. Journal of the American Academy of Child and Adolescent Psychiatry, 35, 215-222.

Rickwood,D.J., \& Braithwaite,V.A. (1994). Social-psychological factors affecting helpseeking for emotional problems. Social Science and Medicine, 39, 563-572.

Saunders, S.M., Resnick, M.D., Hoberman, H.M., \& Blum, R.W. (1994). Formal help-seeking behavior of adolescents identifying themselves as having mental health problems. Journal of the American Academy of Child and Adolescent Psychiatry, 33, 718-728.

Sawyer, M.G., Arney, F.M., Baghurst, P.A., et al. (2000). The mental health of young people in Australia: Child and adolescent component of the national survey of mental health and well-being. Canberra: Commonwealth Department of Health and Aged Care.

Sawyer, M.G., Arney, F.M., Baghurst, P.A., et al. (2001). The mental health of young people in Australia: Key findings from the child and adolescent component of the national survey of mental health and wellbeing. Australian and New Zealand Journal of Psychiatry, 35, 806-814.

Sayal, K., \& Taylor, E. (2004). Detection of child mental health disorders by general practitioners. British Journal of General Practice, 54, 348-352.

Shaffer,D., Fisher, P., Christopher, P.L., Dulcan, M.K., \& Schwab-Stone, M.E. (2000). NIMH Diagnostic Interview Schedule for Children Version IV (NIMH DISC-IV): Description, differences from previous versions, and reliability of some common diagnoses. Journal of the American Academy of Child and Adolescent Psychiatry, 39, 28-38.

Sourander, A., Helstelä, L., Ristkari,T., Ikäheimo, K., Helenius, H., \& Piha, J. (2001). Child and adolescent mental health service use in Finland. Social Psychiatry and Psychiatric Epidemiology, 36, $294-298$.

Stanger, C., \& Lewis, M. (1993). Agreement among parents, teachers, and children on internalising and externalising behavior problems. Journal of Clinical Child Psychology, 22, 107-115.

Tucker, L.R., \& Lewis, C. (1973). A reliability coefficient for maximum likelihood factor analysis. Psychometrika, 38, 1-10 Verhulst, F.C., \& Koot, J.M. (1992). Child psychiatric epidemiology: Concepts, methods and findings. Beverly Hills, CA: SAGE Publications.

Verhulst, F.C., Van der Ende, J., Ferdinand, R.F., \& Kasius, M.C. (1997). The prevalence of DSM-III-R diagnoses in a national sample of Dutch adolescents. Archives of General Psychiatry, 54, 329-336.

Walker, Z., \& Townsend, J. (1998). Promoting adolescent mental health in primary care: A review of the literature. Journal of Adolescence, 21, 621-634.

Westert,G.P., Schellevis, F.G., De Bakker,D.H., Groenewegen, P.P., Bensing, J.M., \& Van der Zee, J. (2005). Monitoring health inequalities through general practice: The second Dutch National Survey of General Practice. European Journal of Public Health, 15, 59-65.

Wissow, L.S., Roter,D.L., \& Wilson, M.E. (1994). Pediatrician interview style and mothers' disclosure of psychosocial issues. Pediatrics, 93, 289-295.

Zwaanswijk, M.,Van der Ende, J.,Verhaak, P.F. M., Bensing, J.M., \& Verhulst, F.C. (2003). Factors associated with adolescent mental health service need and utilization. Journal of the American Academy of Child and Adolescent Psychiatry, 42, 692-700.

Zwaanswijk, M.,Van der Ende, J.,Verhaak, P.F. M., Bensing, J.M., \& Verhulst, F.C. (2005). Help-seeking for child psychopathology: Pathways to informal and professional services in The Netherlands. Journal of the American Academy of Child and Adolescent Psychiatry, 44, 1292-1300. 
Zwaanswijk, M., Ende, J. van der, Verhaak, P.F.M., Bensing, J.M., Verhulst, F.C. The different stages and actors involved in the process leading to the use of adolescent mental health services. Clinical Child Psychology and Psychiatry: 2007, 12(4), 567-582

\section{TABLES}

Table I. Frequencies of deviant Total Problems scores and overlap between informants

\begin{tabular}{|c|c|c|c|c|c|c|c|}
\hline & & \multicolumn{2}{|l|}{ Boys } & \multicolumn{2}{|l|}{ Girls } & \multicolumn{2}{|l|}{ Total } \\
\hline & & $\%$ & $N$ & $\%$ & $N$ & $\%$ & $N$ \\
\hline \multirow{7}{*}{ Total Problems in deviant range } & $P$ & 65.5 & $38(58)$ & 52.7 & $29(55)$ & 59.3 & $67(113)$ \\
\hline & A & 21.1 & $12(57)$ & 28.3 & $15(53)$ & 24.5 & $27(110)$ \\
\hline & $\mathrm{T}$ & 60.5 & $26(43)$ & 53.7 & $22(4 I)$ & 57.1 & $48(84)$ \\
\hline & $P+A$ & 14.0 & $8(57)$ & 9.6 & $5(52)$ & 11.9 & $13(109)$ \\
\hline & $P+T$ & 23.3 & $10(43)$ & 9.8 & $4(4 I)$ & 16.7 & $14(84)$ \\
\hline & $A+T$ & 4.7 & $2(43)$ & 2.6 & I (39) & 3.7 & $3(82)$ \\
\hline & $P+A+T$ & 4.7 & $2(43)$ & - & - & 2.4 & $2(82)$ \\
\hline
\end{tabular}

Note. P: Parent; A: Adolescent; T: Teacher. In parentheses are the numbers of respondents for whom data were available.

Table 2. Means and standard deviations of continuous Total Problems scores

\begin{tabular}{|c|c|c|c|c|c|c|c|}
\hline & \multirow[b]{2}{*}{ Informant } & \multicolumn{2}{|l|}{ Boys } & \multicolumn{2}{|l|}{ Girls } & \multicolumn{2}{|l|}{ Total } \\
\hline & & Mean & $S D$ & Mean & $S D$ & Mean & $S D$ \\
\hline \multirow{3}{*}{ Total Problems } & Parent & 35.0 & I8.3 (58) & 30.9 & I6.8(55) & 33.0 & $17.6(113)$ \\
\hline & Adolescent & 38.3 & $16.5(57)$ & 40.3 & $21.0(53)$ & 39.2 & $18.8(110)$ \\
\hline & Teacher & 35.6 & $23.8(43)$ & 28.0 & $20.5(4 I)$ & 31.9 & $22.4(84)$ \\
\hline
\end{tabular}

Note. In parentheses are the numbers of respondents for whom data were available. 
Zwaanswijk, M., Ende, J. van der, Verhaak, P.F.M., Bensing, J.M., Verhulst, F.C. The different stages and actors involved in the process leading to the use of adolescent mental health services. Clinical Child Psychology and Psychiatry: 2007, 12(4), 567-582

Table 3. Psychiatric DSM-IV diagnoses according to parent report (DISC-P) and adolescent self-report (DISC-Y)

\begin{tabular}{|c|c|c|c|c|c|c|}
\hline \multirow[b]{2}{*}{ Psychiatric diagnoses } & \multicolumn{3}{|c|}{ Parent report } & \multicolumn{3}{|c|}{ Adolescent report } \\
\hline & $\begin{array}{l}\text { Girls } \\
N=26\end{array}$ & $\begin{array}{l}\text { Boys } \\
N=34\end{array}$ & $\begin{array}{l}\text { Total } \\
N=60\end{array}$ & $\begin{array}{l}\text { Girls } \\
N=24\end{array}$ & $\begin{array}{l}\text { Boys } \\
N=12\end{array}$ & $\begin{array}{l}\text { Total } \\
N=36\end{array}$ \\
\hline Emotional & $22(84.6 \%)$ & $17(50.0 \%)$ & $39(65.0 \%)$ & $21(87.5 \%)$ & $7(58.3 \%)$ & $28(77.8 \%)$ \\
\hline Agoraphobia & 3 & - & 3 & 5 & - & 5 \\
\hline Generalized anxiety & - & 1 & I & - & - & - \\
\hline Obsessive-compulsive & & & & & & \\
\hline disorder & 2 & - & 2 & 4 & 1 & 5 \\
\hline Panic disorder & 2 & - & 2 & 4 & - & 4 \\
\hline Posttraumatic stress & & & & & & \\
\hline disorder & 1 & I & 2 & 2 & - & 2 \\
\hline Separation anxiety & 3 & 2 & 5 & - & 1 & 1 \\
\hline Social phobia & 2 & 4 & 6 & 1 & 3 & 4 \\
\hline Specific phobia & 5 & 7 & 12 & 3 & 1 & 4 \\
\hline Mania & 1 & - & I & - & 1 & 1 \\
\hline Major depression & 1 & 1 & 2 & 2 & - & 2 \\
\hline Dysthymia & 2 & I & 3 & - & - & - \\
\hline $\begin{array}{l}\text { Behavioural } \\
\text { Attention-deficit }\end{array}$ & $4(15.4 \%)$ & $17(50.0 \%)$ & $21(35.0 \%)$ & $3(12.5 \%)$ & $5(41.7 \%)$ & $8(22.2 \%)$ \\
\hline hyperactivity disorder & 1 & 9 & 10 & 2 & 2 & 4 \\
\hline $\begin{array}{l}\text { Conduct disorder } \\
\text { Oppositional defiant }\end{array}$ & - & 2 & 2 & - & 2 & 2 \\
\hline disorder & 3 & 6 & 9 & 1 & I & 2 \\
\hline
\end{tabular}

Note. $N$ represents the total number of psychiatric diagnoses in the indicated group. 
Zwaanswijk, M., Ende, J. van der, Verhaak, P.F.M., Bensing, J.M., Verhulst, F.C. The different stages and actors involved in the process leading to the use of adolescent mental health services. Clinical Child Psychology and Psychiatry: 2007, 12(4), 567-582

Table 4. Frequencies of service need and service use

\begin{tabular}{|c|c|c|c|c|c|c|c|}
\hline & \multirow[b]{2}{*}{ Informant } & \multicolumn{2}{|l|}{ Boys } & \multicolumn{2}{|l|}{ Girls } & \multicolumn{2}{|l|}{ Total } \\
\hline & & $\%$ & $N$ & $\%$ & $N$ & $\%$ & $N$ \\
\hline \multirow[t]{3}{*}{ Service need } & $\mathrm{P}$ & 26.3 & $15(57)$ & 18.9 & $10(53)$ & 22.7 & $25(110)$ \\
\hline & A & 10.4 & $5(48)$ & 16.7 & $8(48)$ & 13.5 & $13(96)$ \\
\hline & $P+A$ & 4.3 & $2(47)$ & 2.2 & I (45) & 3.3 & $3(92)$ \\
\hline \multicolumn{8}{|l|}{ Service use } \\
\hline General practice & $\mathrm{P}$ & 14.0 & $8(57)$ & 15.4 & $8(52)$ & 14.7 & $16(109)$ \\
\hline Mental health care & $\mathrm{P}$ & 14.0 & $8(57)$ & 19.2 & $10(52)$ & 16.5 & $18(109)$ \\
\hline Teacher & $\mathrm{P}$ & 26.3 & $15(57)$ & 23.1 & $12(52)$ & 24.8 & $27(109)$ \\
\hline Friends/relatives & $\mathrm{P}$ & 26.3 & $15(57)$ & 28.8 & $15(52)$ & 27.5 & $30(109)$ \\
\hline
\end{tabular}

Note. P: Parent; A: Adolescent. In parentheses are the numbers of respondents for whom data were available.

Table 5. Fit measures of subsequent models in the process of improving model fit

\begin{tabular}{lllllll}
\hline Model & $\chi^{2}$ & $d f$ & $p$ & NNFI/TU & RMSEA & $90 \% \mathrm{Cl}$ \\
\hline $\mathrm{A}$ & 32.15 & 20 & .04 & .96 & .07 & $.01-.12$ \\
$\mathrm{~B}$ & 35.88 & 26 & .09 & .98 & .06 & $.00-10$ \\
$\mathrm{C}$ & 30.32 & 25 & .21 & .99 & .04 & $.00-.09$ \\
$\mathrm{D}$ & 33.20 & 28 & .23 & .99 & .04 & $.00-.09$ \\
Multigroup & & & & & & \\
E & 64.50 & 56 & .18 & .98 & .04 & $.00-.07$ \\
F & 69.26 & 63 & .27 & .99 & .03 & $.00-.07$ \\
\hline
\end{tabular}

Note. NNFI/TLI: Non normed fit index/Tucker-Lewis coefficient; RMSEA: Root Mean Square Error of Approximation; $\mathrm{Cl}$ : Confidence interval.

\section{FIGURES}


Zwaanswijk, M., Ende, J. van der, Verhaak, P.F.M., Bensing, J.M., Verhulst, F.C. The different stages and actors involved in the process leading to the use of adolescent mental health services. Clinical Child Psychology and Psychiatry: 2007, 12(4), 567-582

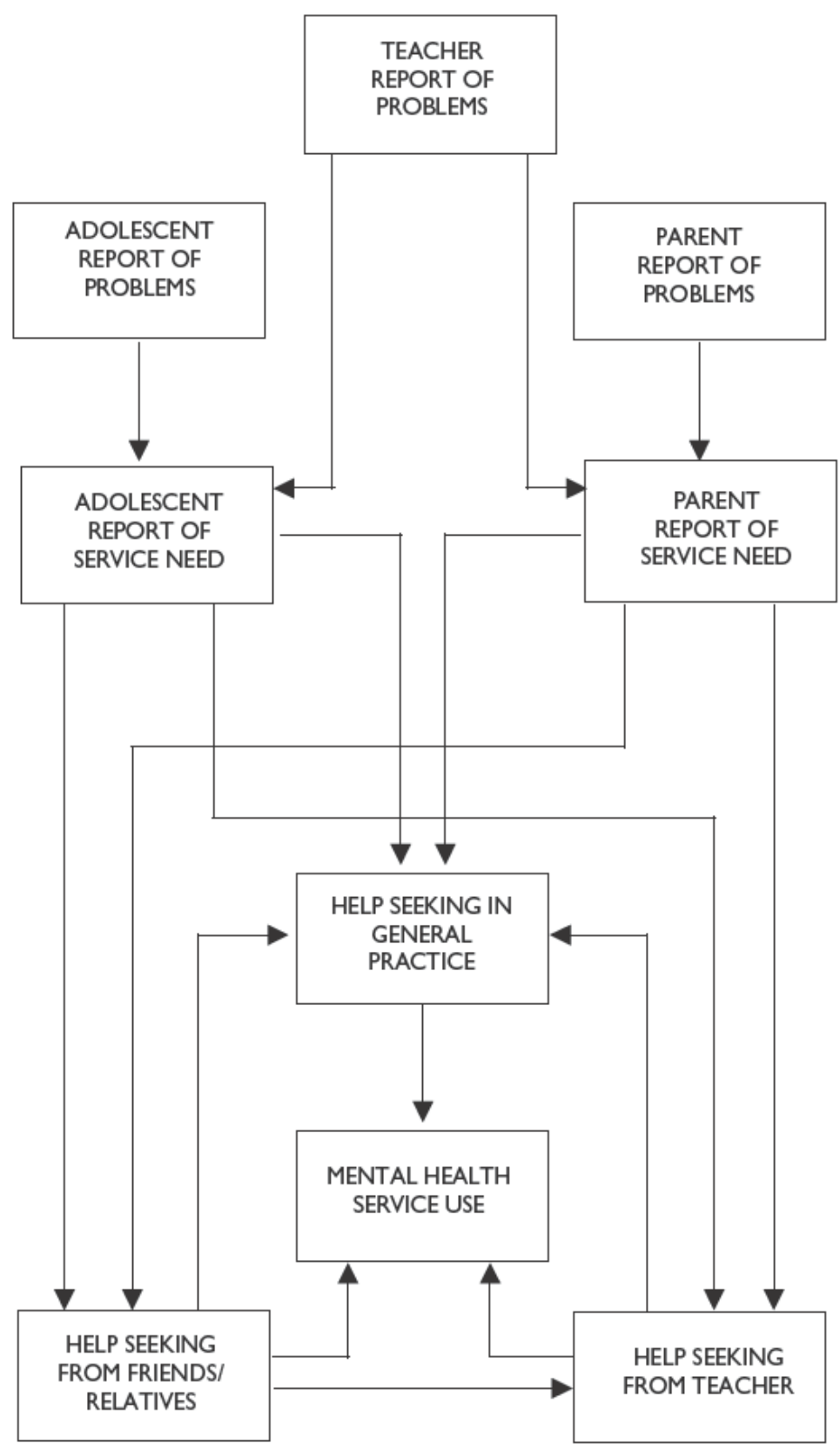

Figure I. Theoretical model of the help-seeking process for adolescent psychopathology. 
Zwaanswijk, M., Ende, J. van der, Verhaak, P.F.M., Bensing, J.M., Verhulst, F.C. The different stages and actors involved in the process leading to the use of adolescent mental health services. Clinical Child Psychology and Psychiatry: 2007, 12(4), 567-582

\begin{tabular}{|c|}
\hline $\begin{array}{l}\text { Base population: Dutch National Survey of General Practice } \\
\qquad \begin{array}{c}\text { Listed patients: } N=385,46 \text { I } \\
28,324 \text { respondents aged I } 2-17 \text { years }\end{array}\end{array}$ \\
\hline$\downarrow$ \\
\hline Stage I: Health interview survey \\
\hline Approached: $N=19,685$ \\
\hline Responded: $N=12,699$ \\
\hline 934 respondents aged $12-17$ years \\
\hline Screening during health interview \\
\hline Approached: $N=934$ \\
\hline Responded: $N=830$ \\
\hline$\downarrow$ \\
\hline Stage II: Psychiatric and help-seeking interview \\
\hline Approached: $N=|9|$ \\
\hline Responded: $N=114$ \\
\hline
\end{tabular}

Figure 2. Study design and numbers of respondents at various stages of the study. 


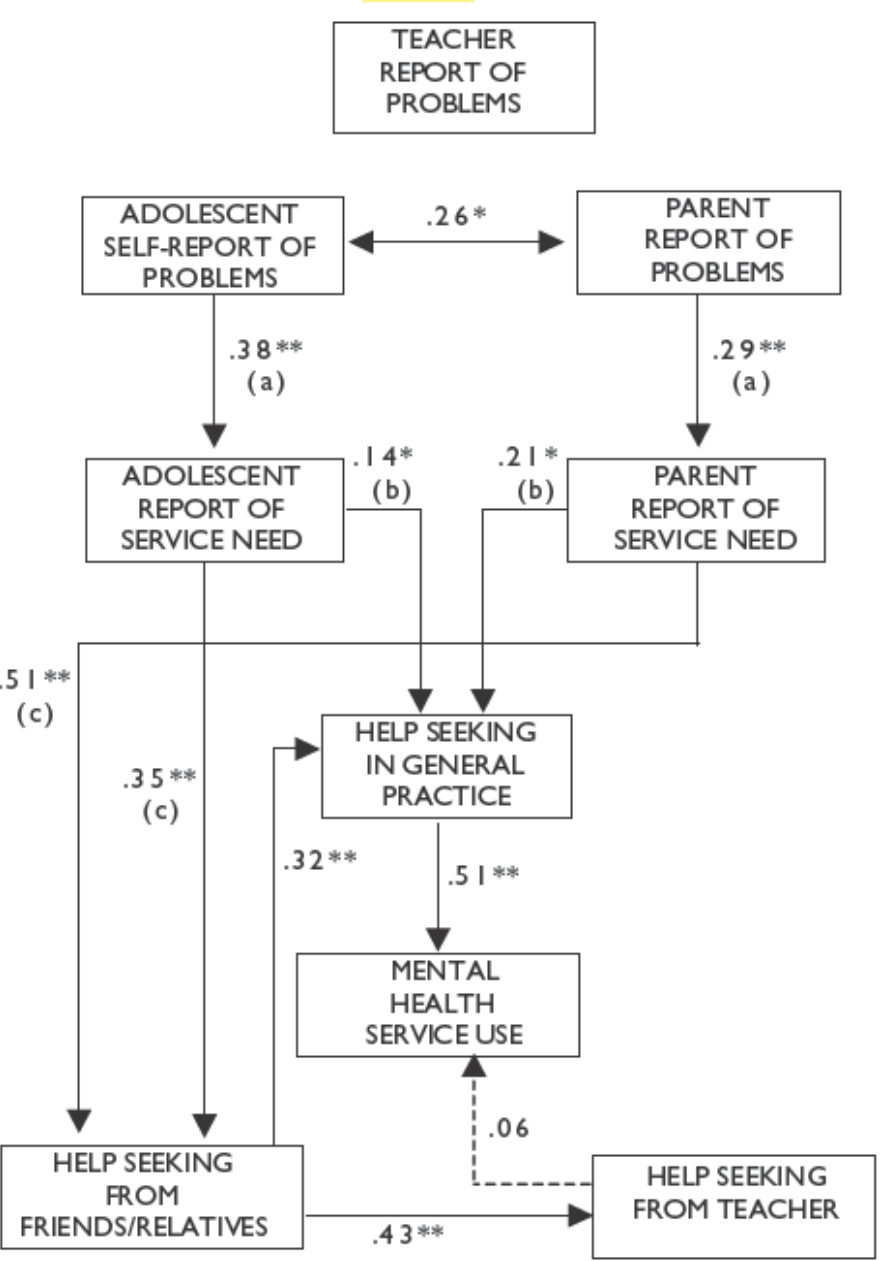

Boys' model

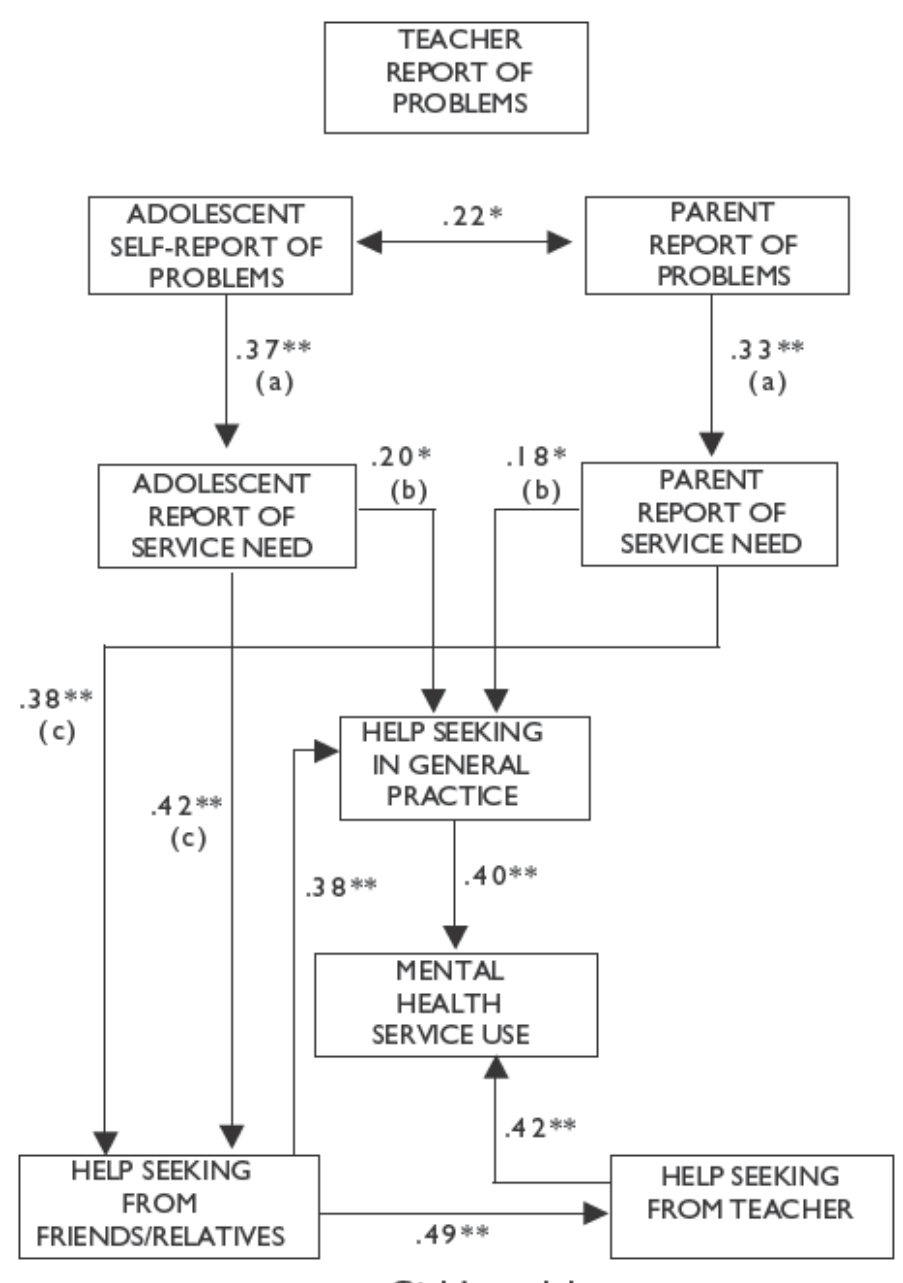

Girls' model

Figure 3. Final model of the help-seeking process for adolescent psychopathology, reported separately for boys and girls.

Note: Presented are standardized regression weights (single-headed arrows), correlations (double-headed arrows), and a nonsignificant association (dashed line). Paths with (a), (b), and (c) were constrained to be equal across parents and adolescents. $* p<.05$; ** $p<.0$ I. 